\title{
CONGENITA PTOSIS; FREQUENCY OF CONGENITAL PTOSIS.
}

1. MBBS (Pb), M.Phil (Anatomy), FCPS (G. Surgery)

Associate Professor Anatomy Islamic International Medical College Rawalpindi.

Correspondence Address: Dr. Sikander Hayat Khan Niazi House No.414 Chaklala Scheme III, Rawalpindi.

sikanderz@rocketmail.com

Article received on:

15/10/2019

Accepted for publication: 30/12/2019

\begin{abstract}
Sikander Hayat Khan Niazi
ABSTRACT... Objectives: To compare the frequency of congenital ptosis of Pakistani children with the children of the world. Study Design: Comparative study. Setting: Al Shifa Tertiary Eye Hospital Rawalpindi. Period: August 2013 to September 2016. Material \& Methods: The record of admitted patients of all malformations of eyes was collected from pediatric eye department from age zero to 15 years. Seven groups of age were made with 2 years difference between each group starting from age 0 to 15 years. The number of male and females were calculated in each age group. Total numbers of each malformation was calculated separately and percentage of each malformation calculated as per simple mathematical way to total malformations. Results: The data of five hundreds and fourteen congenital malformations of eyes was collected. The numbers of male patients were 289 and female patients were 225 . As per percentage the males were $56.2 \%$ and females patients were $43.8 \%$. The patient age range was from age zero to fifteen years. The majority of the patients were between ages zero to two years. The total numbers of patients in this age group were 222. Out of 222 patients the males were 120 and females were 102. The total percentage of this age group was $43.2 \%$ among all age groups. The most common frequency of eye malformation was cataract i.e. $116(22.6 \%)$ patients followed by lacrimal apparatus anomalies i.e. 103(20\%) and ptosis was 45 (8.8\%). Conclusion: The frequency of congenital ptosis is the third most common eye malformation among total eye malformations in this study.
\end{abstract}

Key words: Congenital Ptosis, Congenital Malformations, Frequency.

Article Citation: Niazi SHK. Congenita ptosis; Frequency of congenital ptosis. Professional Med J 2020; 27(8):1602-1605. DOI: 10.29309/TPMJ/2020.27.08.4250

\section{INTRODUCTION}

Ptosis is Greek word meaning, to fall. Ptosis refers blepharoptosis or drooping of upper eye lid which is 1 to $2 \mathrm{~mm}$ below to the corneoscleral limbus. ${ }^{1}$ The congenital ptosis may be present since birth or occur within first year of life. ${ }^{2}$

The muscles of upper eye lids i.e. Levator palpebrae superioris, its somatic part is innervated by ipsilateral oculomotor nerve and adjacent smooth muscle is supplied by sympathetic fibers emerging from first thoracic segment of spinal cord. ${ }^{3}$ The muscles of upper eyelid are responsible for drooping which may be due to loss of muscular or nerve functions and condition may be unilateral or bilateral. ${ }^{4}$

Congenital ptosis is usually in isolation but sometimes it is component of other ocular or systemic disorders. ${ }^{5}$ Congenital ocular and systemic anomalies are rare association with congenital ptosis but ophthalmologists should observe these malformations. ${ }^{6}$ In cases of moderate to severe congenital ptosis, the systemic disorders are frequent. ${ }^{7}$ The eye and systemic examinations are essential in severe cases of congenital ptosis. ${ }^{8}$ Ambylopia is much higher in congenital ptosis. ${ }^{9}$

Although congenital ptosis is non-progressive disease but it can cause functional and psychological problems. ${ }^{10}$

The amblyopia risk, ptosis grade and function of levator muscle of eyelid are the guide lines for choice and timing of surgery. ${ }^{11}$

\section{MATERIAL \& METHODS}

The record of the admitted patients from the admission register of pediatric eye department of Al-Shifa tertiary eye hospital Rawalpindi was 
observed from August 2013 to September 2016. From this record the congenital eye malformations were noted. The patients record papers collected from the record room. From the history and diagnosis required information were recorded. Only the patients between ages zero to 15 years were included in this study.

The required data included the age, gender and final diagnosis of the patients. All the data was tabulated by two ways. In one way, the seven age groups were made, spacing 2 years gap between each group from age zero to fifteen years. These groups were further separated into male and female patients. The percentage of each age group was calculated among the total patients by simple mathematical calculations. Furthermore male and female patient percentage was also calculated by same method. The second table was made by tabulating various congenital eye malformations according to descending order of total number of patients of the malformations. The percentage of each malformation was noted by simple mathematical calculations.

Percentage of malformation $=$ Total number of particular malformation

Total number of patients

\section{RESULTS}

The results are tabulated in Table-I and TableII. The Table-I includes age groups and gender distributions with percentage of each age group. The patient's age range was from age zero to fifteen years. The major bulk of the patients i.e.222, were between births to two years.

\begin{tabular}{|l|c|c|c|c|}
\hline $\begin{array}{c}\text { Age } \\
\text { (Years) }\end{array}$ & Male & Female & Total & $\%$ \\
\hline $0-2$ & 120 & 102 & 222 & 43.2 \\
\hline $2.1-4$ & 35 & 30 & 65 & 12.6 \\
\hline $4.1-6$ & 40 & 26 & 66 & 12.8 \\
\hline $6.1-8$ & 34 & 21 & 66 & 12.8 \\
\hline $8.1-10$ & 33 & 23 & 56 & 10.9 \\
\hline $10.1-12$ & 22 & 19 & 41 & 08.0 \\
\hline $12.1-15$ & 05 & 04 & 09 & 01.8 \\
\hline Total & 289 & 225 & 514 & 100 \\
\hline \multicolumn{7}{|c|}{ Table-I. Distribution by age and gender } \\
\hline
\end{tabular}

In Table-Il the congenital malformations are tabulated according to total numbers of the each malformation in descending order. There are total five hundreds and fourteen congenital malformations. The common causes of congenital anomalies of eyes were, cataract $22.6 \%$, lacrimal apparatus $20 \%$, ptosis $8.8 \%$, pigmentary retinal degeneration $6.8 \%$,micro-ophthalmos/an-ophthalmos $5 \%$, optic atrophy $4.5 \%$ Duanes syndrome $3.89 \%$, congenital glaucoma $3.3 \%$.

\begin{tabular}{|l|c|c|}
\hline \multicolumn{1}{|c}{ Disease } & Total & $\%$ \\
\hline Cataract & 116 & 22.60 \\
\hline Lacrimal apparatus anomalies & 103 & 20.00 \\
\hline Congenital Ptosis & 45 & 8.80 \\
\hline Pigmentary retinal degeneration & 35 & 6.80 \\
\hline Anophthalmos/micro-ophthalmos & 26 & 5.00 \\
\hline Optic atrophy & 23 & 4.50 \\
\hline Duane syndrome & 20 & 3.89 \\
\hline Congenital glaucoma & 17 & 3.30 \\
\hline Coloboma(lid, uveal, retinal) & 15 & 2.91 \\
\hline Maculopathy & 14 & 2.72 \\
\hline Albinism & 13 & 2.33 \\
\hline Retinoblastoma & 11 & 2.14 \\
\hline Ectopic lentis & 09 & 1.75 \\
\hline Blephrophymosis & 08 & 1.55 \\
\hline Dermoid cyst & 06 & 1.16 \\
\hline Double elevator palsy & 06 & 1.16 \\
\hline Mesodermal dysgenesis & 06 & 1.16 \\
\hline Congenital retinal detachment & 06 & 1.16 \\
\hline Other cases & 49 & 9.53 \\
\hline Total & 514 & 100 \\
\hline \multicolumn{2}{|c|}{ Table II. Types and frequency of congenital } \\
\multicolumn{2}{|c|}{ malformations } & \multicolumn{2}{|c}{} \\
\hline
\end{tabular}

The ptosis cases were 45 out of five hundreds and twelve. Only 3 patients had bilateral ptosis and out of remaining, 25 left eyes and 17 right eyes were involved. Out of total 45 patients, 25 were males and 20 were females.

\section{DISCUSSION}

Early diagnosis, management and rehabilitation of the patients are the key success of all eyes congenital anomalies including congenital ptosis.

Ptosis (Simple congenital, the commonest form of ptosis) was $3^{\text {rd }}$ most common lid condition after entropion and chalazion in oculoplastic clinic. ${ }^{12}$ 
Simple congenital ptosis was the most prevalent form, occurring in 1 in 842 births, in a study of 40 years (from Jan. 1965 to Dec. 2004) of the residents of Oimosted County, Minisota. ${ }^{13}$

Berry -Brincat and Willsha W reviewed all cases of childhood ptosis at the Birmingham Children Hospital over a period of 10 years and found incidence of congenital ptosis at $41 \%$ (76 out of 186 children). ${ }^{14}$

During recent study in outpatient ophthalmology department of Gauhati Medical College Gauhati, 140 patients had eye anomalies out of 3102 eye patients. Out of these ocular malformations, congenital cataract was $30.71 \%$, globe anomalies $21.42 \%$, and congenitall ptosis $10.72 \%$. ${ }^{15}$

At a tertiary referral center in Logos, Nigeria, 20 months record of pediatric eye department was analyzed. The 40 pediatric patients out of 412 had congenital anomalies of eyes. The common congenital anomalies were cataract (39.1\%), Ptosis (17.4\%) and glaucoma (8.7\%). ${ }^{16}$

Out of 78 cases of congenital eye malformations, congenital ptosis were $12(15.4 \%)$ glaucoma $10(12.8 \%)$ and esotopia $9(11.5 \%)$ in a study of North Westeren Nigeria. ${ }^{17}$

The record of 1740 patients was analyzed in Zaire from 1962-1992. The congenital eye anomalies were $2.2 \%$. Out of these congenital cataract (38\%), congenital nasolacrimal duct obstruction $(10 \%)$, congenital glaucoma $(9 \%)$ and ptosis $(8 \%) .{ }^{18}$

Between 2004-2009, in a Teaching Hospital Ghana, 263 patients were diagnosed with at least one eye anomaly. The most frequent anomaly was cataract $16.8 \%$ followed by glaucoma $14.1 \%$. esotropia $11.1 \% /$ and Ptosis $5.7 \% .{ }^{19}$

Out of 2254 children (0-5 years) examined at ophthalmology unit at Yaounde Gynae and Pediatric hospital (From Jan 2003 to Dec.2009), 150 presented eye anomalies. The most common anomalies were congenital lacrimal duct obstruction (66.66\%), congenital cataract (10.9\%) congenital glaucoma (10.9\%) and congenital ptosis $(3.77 \%) .{ }^{20}$

\section{CONCLUSION}

The frequency of congenital ptosis is the third most common eye malformation among total eye malformations in this study.

\section{Copyright@ 30 Dec, 2019.}

\section{REFERRENCES}

1. Jordan D, Mawn L, Anderson RL. Surgical anatomy of the ocular adnexa: A clinical approach. $2^{\text {nd }}$ ed. New York: Oxford University Press; 2012.

2. Marenco M, Macchi I, Galassi E. Clinical presentation and management of congenital ptosis. Clin Ophthalmol. 2017; 11: 453-63.

3. Chummy SS. Last's anatomy, regiona and applied. $12^{\text {th }}$ ed. Churchill Livingstone: ELSEVIER: 2011.

4. Soohoo JR, Davies BW, Allard FD, Durairaj VD. Congenital ptosis. Surv Ophthalmol. 2014; 59(5): 4839.

5. Mulvihill A, O Keefe M. Classification, assessment and management of childhood ptosis. Opthalmology Clinic of North America. 2001; 14(3): 447-55.

6. Ornek N, Hosal BM, Zilelioglu D. Congenital ptosis and associated congenital malformations. J of American Asso for Pediatric Ophthalmol and Strabismus. 2004; 8(3): 293-5.

7. Stein A, Kelly JP, Weiss AH. Congenital eye ptosis: Onset and prevalence of ambylopia, associations with systemic disorders and treatment outcomes. J Pediatr. 2014; 165(4):820-4.

8. Michelle WL, Alison BH, Douglas PM, Joseph NG. Clinical evaluation of blepharoptosis: Distinguishing age related ptosis from masquerade conditions. Semin Plast Surg. 2017; 31(1): 5-16.

9. Junior G, AstorBranco, Exterhotter FR. Epidemiological profile of congenital ptosis patients in the hospital regionalde Sao Jose. Revista Brasileira de Oftalmologia.2011; 70: 391-5.

10. Berry-Brincat $A$, Willshaw $H$. Paediatric blephroptosis: A 10 year review. Eye (lond). 2009; 23: 1554-9.

11. Marenco M, Macchi I, Galassi E. Clinical presentation and management of congenital ptosis. Clinical Ophthalmol.2017; 11: 453-63. 
12. Gautam P, Adhikari R, Sharma BR. Etiopathogenetic patterns of blepharoptosis in Westeren Nepal: An Overview. Nepal J Ophthalmol. 2016; 8(15): 36-40.

13. Griepentrog GJ, DiehI NN, Mohney BG. Incidence and demographics of childhood ptosis. Pphthalmology. 2011; 118(6): 1180-83.

14. Berry-Brincat $A$, Willshaw $H$. Paediatric blepharoptosis: A 10-year review. Eye. 2009; 23(7):1554-59.

15. Iqbal J, Deka, Sultan S. A clinical study of congenital and developmental ocular anomalies in paediatric age group. Int. J current Advanced Res. 2019; 8: 1885457.

16. Adekoya BJ, Balogun M, Balogun BG. Spectrum of congenital defects of eye and its adnexa in the pediatric age group; Experience at a tertiary facility in Nigeria. Int. Ophthalmol.2014; 35(3): 311-17.
17. Monsudi KF, AyanniyiAA, Laval TO, AdepojuFG, SAka ES. Paediatric ocular and adnexa malformation in Birnin Kebbi, North Western Nigeria. Reseach. J. Health Sciences. April-June 2015; 3(2): 91-4.

18. Kaimbo, Mwilambwe, Kamembe. Congenital malformations of the eye ball and its appendices in Zaire. Bull Soc Belge Ophthalmol.1994; 254: 165-70.

19. Ilechie AA, Essuman IVA, Enyionam S. Prevalence of congenital eye anomalies in a paediatric clinic in Ghana. Eastern Mediterranian Health Journal. 2013(3); 76-80.

20. Andre OE, Augustin E, Godefroy K, Ngoune C.N. Eye malformations in Cameroonian children: A clinical survey. Clinical Ophthalmol.October 2012; 6(1): 160711.

\begin{tabular}{|c|c|c|c|}
\hline \multicolumn{3}{|c|}{ AUTHORSHIP AND CONTRIBUTION DECLARATION } \\
\hline Sr. \# & \multicolumn{1}{|c|}{ Author(s) Full Name } & Contribution to the paper & Author(s) Signature \\
\hline 1 & $\begin{array}{l}\text { Sikander Hayat Khan } \\
\text { Niazi }\end{array}$ & $100 \%$ & \\
\hline
\end{tabular}

